\section{Percepção de acadêmicos surdos sobre a Plataforma Virtual Moodle}

\section{Perception of Deaf academics on the virtual Platform Moodle}

Percepción de académicos sordos sobre la Plataforma Virtual Moodle

kellyloddo@ufpr.br

Universidade Federal do Paraná (UFPR)

\section{Adriano de Souza Pereira (D) 9}

adriano1509pereira@gmail.com

Universidade Federal do Paraná (UFPR)

\section{Katherine Fischer (iD) 9}

kathe.fischer@gmail.com

Universidade Federal do Paraná (UFPR)

\section{Resumo}

A pesquisa teve por objetivo investigar a percepção de acadêmicos surdos sobre o uso da plataforma virtual Moodle. Para tanto, optou-se por uma investigação de cunho exploratório, de caráter descritiva, com quinze acadêmicos surdos. A coleta de dados se deu através de entrevistas semiestruturadas (escrita do português e sinalizada em Libras), que versou sobre suas percepções quanto ao uso da plataforma, bem como seus recursos no contexto acadêmico. Os resultados mostraram: a) Quanto ao uso da plataforma Moodle: a maioria dos entrevistados, 53,3\%, disseram não se identificar por não gostarem, ao passo que $46,6 \%$ responderam achar interessante, mesmo considerando a baixa acessibilidade linguística; b) no que tange à questão sobre seus recursos (ferramentas), as respostas versaram por três categorias 1) $13,3 \%$ não encontraram dificuldades; 2) 13,3\% encontram dificuldades razoáveis e 3) 73,3\% apresentaram dificuldades em manusear, relacionando-as a duas questões centrais: a) falta de tradução em Libras dos materiais e b) falta de suporte no decorrer da disciplina - prática e conceitual. Os resultados encontrados vão ao encontro das considerações realizadas pela literatura especializada (CORRÊA; CRUZ, 2019), em que os acadêmicos surdos se identificam com o uso de plataforma, definindo-a como interessante e motivadora, porém a falta de acessibilidade linguística os desmotiva. Dessa forma, concluímos que a plataforma Moodle é capaz de auxiliar na aprendizagem dos surdos, mas necessita de uma implementação efetiva do bilinguismo - Libras como primeira língua e a escrita da língua portuguesa como segunda língua.

\section{Palavras-chave}

Libras. Plataforma virtual. Acadêmicos. Ensino.

\section{Abstract}

The research aimed to investigate the perception of Deaf undergraduate students on the use of the virtual platform Moodle. For that, we opted for a exploratory research with descriptive emphasys with fif-

\section{Kelly Priscilla Lóddo Cezar (iD) 0}

\section{Linguagem Foco}

Revista do Programa de Pós-Graduacão em Linguística Aplicada da UECE

FLUXO DA SUBMISSÃO

Submissão do trabalho: $26 / 07 / 2020$ Aprovação do trabalho: 12/08/2021 Publicação do trabalho: 13/10/2021

\section{COMO CITAR}

CEZAR, Kelly Priscilla Lóddo; PEREIRA, Adriano de Souza; FISCHER, Katherine. Percepção de acadêmicos surdos sobre a Plataforma Virtual Moodle. Revista Linguagem em Foco, v.13, n.3, 2021. p. 149-167. Disponível em: https://revistas.uece.br/ index.php/linguagememfoco/article/view/6770.

\section{Plagius}


teen Deaf students. The data collection was based on semi-structured interviews (in written Portuguese and signed Brazilian Sign Language) about their perceptions regarding the use of the platform and its possibilities on the academic environment. The results show that: a) As to the use of the platform, the majority of respondents 53,3\% (8) declared not to identify with it due to personal preference, while 46,6\% (7) declared to find it interesting, despite its low linguistic accessibility; b) Regarding its resources (tools), the answers were divided into three categories: 1) 13,3\% (2) found no difficulties; 2) 13,3\% (2) found considerable difficulties; and 3) $73,3 \%$ (11) had usage difficulties due to two main issues: a) lack of sign language translation of materials; and b) lack of support during the course (both practical and conceptual). The results found are accordingly to what was found on the specialized literature (CORREA, CRUZ, 2019), which reports that Deaf students connect with the usage of the platform, defining it as interesting and motivating, but get discouraged by the lack of linguistic accessibility. Thus, we conclude that Moodle can assist in the learning of the Deaf but it is necessary to effectively implement bilingualism (Brazilian Sign Language as first language and written Portuguese as second language).

\section{Keywords}

Brazilian Sign Language. Virtual platform. Undergraduate. Students.

\section{Resumen}

Este trabajo tuvo el objetivo de investigar la percepción de académicos sordos sobre el uso de la plataforma virtual Moodle. En ese sentido, se decidió por una investigación exploratoria, de carácter descriptivo, con quince académicos sordos. La recolección de datos se realizó por medio de entrevistas semiestructuradas (escrita y señalizada en Libras) que trató acerca de sus percepciones sobre el uso de la plataforma, así como sus recursos en el contexto académico. Los resultados revelaron: a) En cuanto al uso de la plataforma Moodle: la mayoría de los entrevistados 53.3\% (8) dijeron que no se identificaron porque no les gustó, en tanto que 46.6\% (7) manifestaron que les pareció interesante, aunque considerando la baja accesibilidad lingüística; b) en relación a la cuestión sobre sus recursos (herramientas), las respuestas presentaron por tres categorías 1) $13.3 \%$ (2) no encontraron dificultades; 2) $13.3 \%$ (2) encontraron dificultades razonables y 3 ) $73.3 \%$ (11) expresaron dificultades de manejo relacionadas con dos puntos centrales: a) falta de traducción en Libras de los materiales y b) falta de apoyo durante el curso - práctica y conceptual. Los resultados encontrados están de acuerdo con las consideraciones hechas por los expertos (CORRÊA; CRUZ, 2019) en el que los académicos sordos se identifican con el uso de una plataforma, califican como interesante y motivadora, pero la falta de accesibilidad lingüística los desincentiva. Por esta razón, hemos concluido que la plataforma Moodle es capaz de ayudar en el aprendizaje de los sordos, pero necesita de una implementación efectiva del bilingüismo - Libras como primera lengua y la escritura del portugués como segunda lengua.

\section{Palabras-clave}

Libras. Plataforma virtual. Académicos. Enseñanza.

\section{Introdução}

Atualmente nos deparamos com o aceleramento dos usos de ferramentas tecnológicas de maneira descontrolada em razão de uma crise mundial causada na área da saúde - Pandemia (COVID-19)', que sugeriu o isolamento social como estratégia de prevenção. Em razão disso, as aulas presenciais em todos os níveis de escolarização foram suspensas. A partir disso, os estudos online mediados por diferentes ferramentas tecnológicas foram motivos de resistência e, ao mesmo tempo, impulsionaram uma forma rápida do pensar sobre as práticas de ensino tradicionais e tecnicistas existentes. Muitas instituições, em um primeiro

1 É o nome oficial da doença causada pelo novo coronavírus também conhecida como Sars-Cov-2 em razão do Sars-Cov-1 (ou apenas Sars), nome dado à epidemia na China em 2002, por ser considerada "irmãs". Em inglês, Sars-Cov-2 significa: "severe acute respiratory syndrome coronavirus 2", em tradução livre: Síndrome Respiratória Aguda Grave do Coronavírus 2. 
momento, optaram por suspender seus calendários e outras aderiram rapidamente à proposta para ofertarem as aulas a distância. Tanto uma forma quanto a outra tiveram de adaptar seus planos de ensino pensando e repensando o ensino mediado pelas novas tecnologias.

A área da educação se encontrou frente a um novo mundo que necessita, emergencialmente, ser mediado por recursos tecnológicos e de conhecimentos advindos da área de educação a distância, que muito foi e continua sendo criticada, em boa parte por desconhecimento tanto teórico como do funcionamento dos recursos tecnológicos para aprendizagem. No entanto, não há de se negar que os benefícios aparentes para o mundo social, quando se trata de interatividade, de cultura, de informação, de lazer, entre outros que não designam ensino; são utilizados e bem vistos. Na área educacional, acreditamos que os profissionais necessitam estar abertos a novas aprendizagens.

Cabe destacar que não é de hoje, nem tão pouco fundamentados neste período de pandemia mundial, que nosso estudo se insere, mas baseados na literatura especializada na área (KENSKI, 2004; ARCOVERDE, 2006; OLIVEIRA, 2007; AMORIM; SOUZA; GOMES, 2016; GOETTERT, 2014; STUMPF, 2010; FISCHER; CEZAR, 2019), e de nossas pesquisas longitudinais, observa-se o crescimento e a positividade do uso das tecnologias digitais no campo da acessibilidade linguística para a comunidade surda, em especial no ensino superior, permeados pela crise mundial em que o trabalho dos professores foi profundamente afetado (ressignificado) e os desafios com o uso de plataformas virtuais, ferramentas e recursos tecnológicos passaram a ser necessários, exigindo grandes esforços tanto por parte dos docentes quanto dos discentes. Este trabalho tem por objetivo apresentar os resultados referentes às percepções de acadêmicos surdos na plataforma virtual Moodle podendo contribuir de forma teórica e prática neste campo de investigação, já que, neste momento de isolamento, torna-se impossível ficarmos sem pensar sobre as plataformas virtuais, por se tratarem de uma forma de manutenção das práticas de aprendizagem para prevenção da saúde, que se faz necessária. Tal questão foge do nosso controle, temos de aceitar e resolver os desdobramentos negativos e positivos da melhor forma possível. Assim, os recursos tecnológicos entram em cena, confluindo uma questão de saúde e educacional, transformando-se em uma excelente ferramenta para que os educadores se beneficiem e vivenciem a positividade que os recursos tecnológicos

2 Cabe destacar que se trata de um recorte de pesquisa maior longitudinal sobre o uso dessa plataforma para acadêmicos surdos na modalidade híbrida que é dividido em três grandes categorias: 1) acessibilidade na plataforma selecionada; 2) escrita e bilinguismo nos fóruns de aprendizagem; 3) Recursos efetivos de acessibilidade no Moodle. 
educacionais ofertam.

As ferramentas tecnológicas, em conformidade com Arcoverde (2006, p. 252), funcionam como um processo de interações sociais mais amplas que permitem "uma multiplicidade de dinâmicas linguístico-discursivas que possibilitam o uso da linguagem" e ao transpô-las para a área educacional, observa-se que as tecnologias digitais, se fundamentadas, podem se transformar em uma excelente ferramenta metodológica para os aprendizes.

Estendendo essa visão para os recursos de rede, nas formas híbridas (presencial ou a distância), Kenski (2001) tem evidenciado um novo meio de interação gerando novas formas de trabalho, uma vez que não há necessidade de um recurso tecnológico sofisticado, como costumam pensar. A autora chama atenção quanto ao uso do e-mail na área educacional, uma vez que, mesmo sendo considerado a forma mais simples de recurso de rede, exerce diferentes formas de intervenções, tais como receber materiais de estudo, tirar dúvidas, orientação de trabalhos, discussão e interação com alunos. Seguindo essa mesma linha de pensamento, Arcoverde (2006) destaca diversas formas de uso das tecnologias digitais nas práticas educativas a partir das simplicidades tecnológicas. Os resultados de seus estudos evidenciam potencialidade dessas tecnologias pela crescente necessidade dos processos de ensino-aprendizagem em educação a distância mediante propostas como "Educação a distância via Internet" ou "Educação on-line", que, de uma forma mais ampla, acabam por incorporar uma inovadora concepção de aprendizado e de interatividade em diferentes áreas do conhecimento (ARCOVERDE, 2006, p. 256).

Ao transpormos essas considerações para a área de educação bilíngue para surdos, em especial acadêmicos surdos, os resultados são considerados positivos, em especial no que tange à divulgação da Língua Brasileira de Sinais em meios digitais, tecnológicos e plataformas digitais. No entanto, para a efetivação de implementação da proposta metodológica bilíngue para surdos como preconizam os documentos oficiais - Lei 10.436/2002 e Decreto 5626/2005 - e a literatura especializada na área (KUBASKI; MORAES, 2009), há necessidade de respeitar e implementar (efetivar de fato) o bilinguismo para surdos. Outro fator em destaque é o posto por Fischer e Cezar (2019), ao se referirem às dificuldades e às lacunas que qualquer acadêmico necessita para se adaptar, tanto pessoal quanto profissionalmente, para se manter nas universidades. No entanto, quando se referem a acadêmicos surdos, assinalam que essas lacunas "são mais intensas, uma vez que além da comunidade acadêmica não estar preparada para perspectiva bilíngue para surdos, poucos materiais e docentes são fluentes ou conhe- 
cem a língua brasileira de sinais - libras, no Brasil" (FISCHER; CEZAR, 2019, p. 02). As afirmações estão fundamentadas nos resultados de suas investigações com entrevistas individuais com acadêmicos surdos e ancoradas na literatura especializada na área (AMORIM; SOUZA; GOMES, 2016). Dessa forma, salientam que as novas tecnologias são uma grande aliada à acessibilidade linguística aos surdos, uma vez que os suportes tecnológicos, vídeos, Youtube, WhatsApp, plataformas educacionais, maximizam a comunicação articulando diferentes linguagens (desenho, vídeo, ícones, escrita, sinalização), indo ao encontro de uma perspectiva bilíngue de aprendizado efetivo para surdos. Destacamos que em momento algum o uso das tecnologias educacionais dispensará a presença de um professor bem preparado para conduzir o processo de ensino-aprendizagem, no nosso caso, um professor bilíngue.

Para tanto, definimos como discussão central os "problemas" apresentados nas dificuldades relatadas por professores e alunos no ensino bilíngue para surdos, em especial a falta de clareza metodológica da aplicação e das avaliações no que tange às línguas de sinais como primeira língua e a escrita formal do país como segunda língua, considerando os seus movimentos sociais, culturais, econômicos e linguísticos, bem como as políticas linguísticas presentes nesse cenário (BRASIL 2002; 2005).

Com aporte teórico, a pesquisa insere-se no campo da Linguística Aplicada (CESAR; CAVALCANTI, 2007; SIGNORINI; CAVALCANTI, 1998; LOPES,1996; 2013), uma área que, dos anos 1990 para os dias atuais, passou por mudanças fundamentais nos modos de produzir conhecimento, focando em problemas com relevância social para exigir respostas teóricas que trouxessem benefícios sociais a seus participantes (LOPES, 1996), buscando respostas/teorias em outras áreas das Ciências Sociais, como Sociologia, Antropologia, Sociolinguística, o que constitui o seu caráter interdisciplinar, e "espraiando-se para outros contextos" (LOPES, 2009, p. 18), em especial, nesta investigação, as áreas de tecnologias e comunicação para surdos (KENSKI, 2004; ARCOVERDE, 2006; OLIVEIRA, 2007; AMORIN, SOUZA e GOMES, 2016; GOETTERT, 2014; STUMPF, 2010; FISCHER e CEZAR, 2019). Considerando a expansão da Libras no Brasil - obrigatoriedade da disciplina de Libras nos cursos de Licenciatura e Fonoaudiologia - cursos de graduação em Letras Libras, cursos de graduação em Pedagogia Bilíngue, cursos de aperfeiçoamento e extensão - somadas às particularidades estruturais e de funcionamento (visual-espacial), esta pesquisa se caracteriza, principalmente, por ser interdisciplinar e poder contribuir em diferentes áreas do conhecimento quanto ao uso da plataforma Moodle e as percepções que os acadêmicos surdos têm sobre os 
ambientes virtuais de aprendizagem.

\section{Acessibilidade linguística: Libras}

No Brasil, há um aumento de acadêmicos surdos - cerca de 5.404 deficientes auditivos e cerca de 2.138 surdos - matriculados em instituições públicas e privadas (BRASIL, 2018). Tal fato se deve ao reconhecimento da Libras em âmbito nacional (Lei n 10.436/2002), no entanto, a dizimação do conhecimento dessa língua sinalizada deve-se efetivamente ao Decreto $n^{\circ} 5.626 / 2005$, que incorporou a disciplina de Libras como obrigatória, em especial em cursos de licenciatura. Assim, a participação ativa de pessoas com deficiência em diferentes contextos sociais fez as universidades perceberem a necessidade de oferecer acessibilidade aos surdos e a outras pessoas com deficiência.

No entanto, a visão clínica terapêutica ainda é dominante no país e por consequência, por falta de especialistas na área tecnológica, programação e mesmo designer, essa concepção de surdo ou pessoas com deficiência auditiva é concebida a partir de um ponto de vista clínico patológico, o qual se apoia em uma concepção baseada na medicalização, criando avatares ou mesmo recursos sem conhecer a visão socioantropológica da linguagem, defendida pela comunidade surda.

Nesse viés, a surdez é vista como uma deficiência física que precisa de recursos para tornar o surdo uma pessoa "normal"; é percebida como uma anormalidade, uma doença que necessita de cura para que o indivíduo possa ser incluído no grupo considerado padrão, ou seja, o grupo dos ouvintes. Tal perspectiva reconhece a surdez como deficiência auditiva, a qual pode ser quantificada e classificada de acordo com o grau de comprometimento auditivo (grau e/ou intensidade da perda auditiva).

Nas palavras de Silva (2010, p. 09), "a deficiência auditiva é a diminuição da capacidade de percepção normal dos sons, sendo considerado surdo o indivíduo cuja audição não é funcional com ou sem prótese auditiva". Portanto, para os autores que reconhecem a surdez apenas a partir de aspectos orgânicos, a perda auditiva é um fator que impede a percepção, o reconhecimento, a compreensão e a interpretação dos sons, características que requerem um conjunto de estruturas que funcionam com o estímulo sonoro do sistema auditivo humano. Sob esta visão, a deficiência auditiva, ao ser identificada de maneira precoce, pode ser acompanhada por equipe multiprofissional. Nesses casos, a criança pode se desenvolver com maior facilidade, mas, para tanto, é necessário que se 
conheçam as causas e consequências da deficiência auditiva apresentada, para que haja uma intervenção profissional diversificada e ampla, segundo a necessidade de cada indivíduo (SILVA, 2010).

Uma outra maneira de perceber a surdez é a partir de uma perspectiva socioantropológica, a qual aponta que os surdos filhos de pais surdos, usuários da língua de sinais, desenvolvem-se de maneira bastante semelhante às crianças ouvintes. Essa perspectiva explicita que as pessoas precisam de uma língua para interagir, pois é por meio das línguas que nos constituímos como seres humanos, comunicamo-nos com nossos semelhantes, construímos nossas identidades e subjetividades, adquirimos e compartilhamos informações (VYGOTSKY, 1984; SKLIAR, 1997).

A perspectiva socioantropológica de surdez a considera como diferença, valoriza o uso da língua de sinais e não considera a ausência da audição como uma deficiência. Passou a ser discutida no Brasil a partir do final da década de 1980, e segundo Bisol e Sperb (2010), dedica-se a pensar os conceitos de identidade, cultura, poder e linguagem.

Esse modelo apresenta a surdez como uma diferença cultural, vivida por pessoas que fazem parte de uma minoria étnica e linguística, independentemente de seu país de origem, mas que compõem um quadro específico, que foi inicialmente identificado como "virada cultural". No que tange aos surdos, segundo explica Perlin (2004, p. 78),

a virada cultural torna-se visível com as transformações, como a pedagogia de surdos, o atual ensino de língua de sinais, a existência do professor de língua de sinais e do professor surdo, as pesquisas de surdos, os pesquisadores surdos, o modo de vida das famílias surdas, o estilo de vida surda, o aumento de mulheres surdas que residem sozinhas.

Nessa perspectiva, a língua de sinais atua, tanto como símbolo de identidade cultural, como forma de interagir em sociedade, além de fundamentar um meio de aquisição e transmissão de conhecimentos. Nesse sentido, Gesser (2008, p. 232) afirma que a língua de sinais, portanto, "é um símbolo importante de identidade cultural; o que não significa dizer, por outro lado, que o surdo também não construa outras culturas e identidades na língua portuguesa". Dessa forma, entende-se, então, que, a partir da aquisição da língua de sinais, a criança surda constrói sua subjetividade, aproxima-se de seus pares e pode aprender uma segunda língua, no caso do Brasil, a língua portuguesa, tornando-se bilíngue. A língua de sinais, portanto, representa um papel importante na vida dos surdos, 
pois oferece para a criança surda a oportunidade de ter acesso à aquisição de linguagem e de conhecimento de mundo e de si mesma.

A partir do que foi discutido até o momento, cabe esclarecer e expor que este trabalho se afasta de uma visão da linguagem enquanto comunicação, aproximando-se de uma visão que concebe a linguagem como um trabalho dialógico, uma vez que busca aprofundar os estudos linguísticos como prática social em contexto de superdiversidade (VERTOVEC, 2007; BLOMMAERT; RAMPTON, 2011; LOPES, 2009), conforme apresentado a seguir.

\subsection{Linguagem e língua na perspectiva dialógica}

O homem é um ser social que interage com o mundo por meio da linguagem, sob suas variadas formas, o que caracteriza a importância desta durante as interações sociais que se realizam ao longo de toda a vida. Desse modo, as relações sociais estabelecidas entre as pessoas são importantes para que se apropriem da linguagem e constituam-se como sujeitos. Sendo assim, entende-se que, a partir da linguagem, o homem pode argumentar, opinar, informar, aprender, persuadir, educar, socializar, interagir, dialogar, distrair.

A partir dessa perspectiva, concorda-se com a visão de Bakhtin acerca do papel da linguagem nos processos de socialização dos sujeitos, independentemente de serem ouvintes ou surdos, uma vez que é na centralidade da comunicação, do diálogo e da linguagem que o indivíduo alcança a sua inserção na sociedade da qual faz parte (FARACO, 2009).

Conforme expõe Faraco (2009), o ponto de partida de Bakhtin para pensar a linguagem é a utilização da mesma, nas mais diferentes esferas da atividade humana. A linguagem é dialógica, sendo que é por meio das interações que ocorrem todas as mediações durante seu processo de apropriação. Assim, é através da linguagem que as crianças começam a interagir e a se relacionar com o meio em que vivem. Nesse sentido, ao mesmo tempo em que na perspectiva bakhtiniana a interação ganha destaque, é a linguagem que torna possível tais interações, já que não é possível nessa perspectiva pensar em si mesmo sem pensar na relação com o outro. Sob essa perspectiva, a língua passa a ser percebida, não mais como um código pronto e acabado, mas como dialógica. A partir disso, seu uso ocorre por meio de enunciados que acontecem nas interações dialógicas entre sujeito que fazem parte de comunidades linguísticas (BAKHTIN, 2006).

Para Bakhtin (1992), as atividades humanas estão sempre relacionadas ao uso da língua. A língua serve para expressar os enunciados, sejam eles orais 
ou escritos, e a verdadeira substância da língua se manifesta na sua interpretação, constituída como fenômeno social da interação verbal realizada por meio da enunciação ou das emissões. Para o autor citado, a língua não pode estar isolada, fechada, ou seja, desvinculada de seu contexto linguístico real. Pode-se considerar que a língua é utilizada por grupos de indivíduos que formam comunidades linguísticas e que cada grupo possui sua língua, e sua maneira de utilizá-la, de acordo com as influências e necessidades específicas, a exemplo do português, do alemão, dentre outras línguas orais e também das línguas de sinais.

Desse modo, cada língua possui suas particularidades e seus signos linguísticos, determinados por fatores históricos e sociais, sendo que um dos objetivos das línguas é oportunizar as interações entre os grupos que as utilizam. A partir desse conceito, percebe-se que também as línguas de sinais utilizadas pelas comunidades surdas surgem com o objetivo de oportunizar interações entre seus usuários.

É preciso esclarecer que os estudos a respeito das línguas de sinais, em especial a ASL (American Sign Language), datam da década de 1960, a partir dos estudos do linguista Willian Stokoe (1960), que foi o primeiro a descrever os níveis fonológicos e morfológicos dessa língua. Além disso, esse pesquisador apontou alguns dos principais parâmetros da língua de sinais, nomeando-os como configuração de mão (CM), ponto de articulação (PA), e de movimento (M) (LODI, 2004). Além desses parâmetros importantes das línguas de sinais, fazem parte dessa língua outros componentes não manuais, tais como a expressão facial e corporal.

Os sinais dessa língua representam o conjunto de configurações que envolve a configuração das mãos, articulados com movimentos destinados a expressar um significado próprio, pré-determinado, a fim de constituir um meio de comunicação, uma língua. Aliados à disposição e orientação das mãos a língua de sinais é complementada com expressões faciais e corporais, como os recursos auxiliares da construção de sua estrutura sintática (QUADROS, 1997).

No Brasil, pode-se dizer que a difusão da língua de sinais se iniciou tardiamente, já que a escolaridade dos surdos seguiu os preceitos de uma educação baseada em abordagem oralista, na qual apenas o uso da fala era enfatizado (GESSER, 2009; STROBEL, 2009).

A Língua Brasileira de Sinais (Libras) foi reconhecida oficialmente pela Lei $n^{\circ} 10.436 / 2002$ como a primeira língua da comunidade surda brasileira e com essa regulamentação passou a ser discutida a abordagem educacional reconhecida como "bilinguismo". Essa é uma proposta educacional específica para a surdez 
que se fundamenta na possibilidade da presença de duas línguas durante o processo educacional dos surdos, a saber, língua de sinais e a língua portuguesa, por meio das modalidades oral e escrita (QUADROS; KARNOPP, 2004). Comumente identificada como Lei de Libras, teve um papel fundamental, pois a partir dessa lei, as barreiras linguísticas encontradas pelos surdos tendem a ser minimizadas, o que pode melhorar suas condições de interação.

A referida Lei foi regulamentada pelo Decreto $n^{\circ} 5.626 / 2005$, que estabelece, entre outros aspectos, a inclusão da Libras como disciplina curricular nos cursos de licenciaturas e Fonoaudiologia das instituições públicas e privadas de ensino superior, além de direcionar a educação sob a modalidade bilíngue para os surdos que frequentam a educação básica. Essa regulamentação estabelece a garantia do atendimento específico aos alunos com surdez, bem como a presença de um intérprete na sala de aula. Segundo Skliar (2005, p. 27), usufruir da língua de sinais "é um direito dos surdos e não uma concessão de alguns professores e escolas". Isso porque os surdos têm pleno direito de receber uma educação e de se comunicar de forma que privilegie a língua de sinais, a qual, em conformidade com a legislação brasileira, não pode ser negada.

Com relação às metodologias de educação a distância, percebe-se que a língua de sinais, embora seja um direito conquistado desde o ano de 2002, com a aprovação da Lei de Libras, não é levada em consideração nas plataformas virtuais, e a maioria dos materiais didáticos fica à disposição do aluno na modalidade escrita (KUBASKI; MORAES, 2009). A partir desses resultados teóricos, a presente investigação firmou-se em compreender a visão dos acadêmicos surdos na plataforma Moodle. Tal plataforma foi escolhida por ser amplamente difundida em universidades públicas e privadas, além de termos referências a essa plataforma no primeiro curso nacional de Letras Libras, tanto na modalidade licenciatura quanto bacharelado, que ficou reconhecido com nota máxima pelo MEC (2019).

\section{Percurso Metodológico}

Para atingir o objetivo proposto - investigar as percepções de acessibilidade na plataforma virtual Moodle $e^{3}$ de acadêmicos surdos na modalidade híbrida - esta pesquisa foi realizada com cunho exploratório e abordagem descritiva/ explicativa dos dados coletados. Segundo Gil (2007), esse tipo de pesquisa tem

3 A escolha da plataforma investigada se deve por ser a implementada no ensino superior público nacional também utilizada em instituições superiores particulares, ou seja, gratuita e amplamente conhecida. 
como objetivo aprofundar o conhecimento sobre o problema, com o intuito de torná-lo mais explícito. Para tanto, a pesquisa contou com dezesseis acadêmicos surdos que estavam regularmente matriculados no ensino superior da capital de Curitiba/PR e que utilizavam essa plataforma.

Aos participantes foi realizado um convite para participação voluntária seguindo as diretrizes do Comitê de Ética em Pesquisa com Seres Humanos ${ }^{4}$ (CEPE). A escolha seguiu os seguintes critérios de inclusão: a) ser acadêmico surdo; b) estar devidamente matriculado no ensino superior; c) ter concluído uma disciplina na modalidade híbrida no ensino superior (plataforma Moodle) e d) concordar em participar da pesquisa voluntariamente. Quanto ao critério de exclusão: acadêmicos que não aceitaram participar da pesquisa.

Depois dessa fase, aqueles que aceitaram participar assinaram o termo de consentimento livre e esclarecido. Após esclarecidos e de acordo, responderam as seguintes perguntas: 1) Como você avalia a sua utilização da plataforma Moodle? 2) Quais foram suas dificuldades ao utilizar os recursos tecnológicos e a plataforma Moodle? Cabe salientar que as perguntas da coleta ocorreram tendo a Libras como primeira língua e as questões norteadoras disponibilizadas por escrito - português (L2) atendendo os preceitos do bilinguismo. Os participantes também puderam escolher a forma como fariam os registros das respostas, podendo responder em Libras, na forma de vídeo gravado, ou em português, na modalidade escrita. Em seguida, as respostas foram transcritas em português e os participantes deram ciência no material. Os participantes foram devidamente mantidos em sigilo e aqui foram nomeados aleatoriamente como P + numérico, significando $P$ = Participante da pesquisa e a marcação numérica seguindo a ordem em que as entrevistas aconteceram. Vale ressaltar que os participantes não tiveram contato uns com os outros e nem sabiam qual o dia e o horário da entrevista dos demais participantes. A coleta de dados foi realizada durante os meses de junho e julho de 2019. As entrevistas individuais tiveram duração média de 20 minutos.

Dessa forma, analisa-se o conjunto de respostas para compreender a percepção dos acadêmicos surdos na plataforma virtual Moodle. Pretendeu-se observar as questões relativas aos recursos e às dificuldades e facilidades dos recursos dessa plataforma, a fim de transformar e pensar no ensino bilíngue no ensino superior e apresentar os dados para a equipe pedagógica da instituição investigada.

4 Resoluções 466/12 e 510/16. 


\section{Apresentação e discussão dos dados}

Como a área das novas tecnologias está em constante mudança e aperfeiçoamento, necessita do profissional também atualizado. De acordo com Nogueira (2002), os professores têm de estar abertos a essas mudanças rápidas para que, quando necessário, aconteçam de maneira prática e correta, mesmo compreendendo que as mudanças geram novos desafios. Aplicar as novas tecnologias com qualidade na área educacional requer muito envolvimento. As plataformas virtuais disponíveis no Brasil são inúmeras, no entanto, a plataforma investigada é amplamente conhecida nos meios educacionais.

Ao analisarmos as respostas fornecidas pelos quinze acadêmicos surdos investigados Como você avalia a sua utilização de recursos tecnológicos, incluindo a plataforma Moodle, no ensino superior?, que possuem experiência na plataforma e que recentemente haviam passado por disciplinas na modalidade híbrida. Os resultados mostraram que a maioria, 53\% (8), relatam ser um meio de aprendizagem de que não possuem afinidade e devido à falta de acessibilidade linguística, em especial nos materiais traduzidos para LIBRAS, torna-se um fator desmotivador, como evidencia-se nas respostas a seguir:

P1: Precário e confuso.
P3: Moodle ajuda pouco pois falta orientação como estudar Moodle
sabe.
P5: Tem que melhorar muito para os surdos;
P12: Se tiver mais conhecimento sobre a saber de uso o Moodle,
vai ajudar a bastante para acadêmicos a usar com facilidade de
acesso o Moodle, e para mim é razoável de uso Moodle, e sobre
redes sociais, sim uso bastante até mesmo o Google para os
estudos acadêmicos mesmo. Principalmente, Google acadêmico
que é específico na área de artigos, até mesmo tese para fazer as
pesquisas.
P13: Como acadêmico, eu uso recursos tecnológicos sim, mas
a plataforma Moodle da própria universidade, não uso muito.
Porque não tenho interesse e uso só para baixar material e ver os
feedbacks.

P14: Eu uso pouco o que obrigam mesmo, gosto dos vídeos do Youtube e lugares que tem mais libras.

A outra parcela de resposta a essa questão, 46,6\% (7), salientam que a plataforma é boa e gostam, porém, há de se explorar muitos recursos da própria plataforma. 
P2: Eu gosto. Tem uma professora que usa bastante aprendi a gostar. Fica tudo lá e posso consultar sempre.

P8: Eu gosto bastante. Uso sempre para ver e rever os vídeos que consigo ficar voltando sempre que preciso. Tem pouca libras no geral.

P10:Saber usar é o melhor. Difícil entender, depois vai.

P11:Depende da matéria. A plataforma é boa, tem que saber usar.

P15: Gosto, tenho preguiça na verdade.

Pelas respostas da primeira questão sobre a utilização da plataforma, bem como os recursos tecnológicos utilizados pelos acadêmicos surdos no ensino superior dentro e fora dela, notou-se que a maioria dos entrevistados 53,3\% (8) não utilizam a plataforma Moodle por falta de interesse e de acessibilidade. Para esse grupo de respostas dos entrevistados, outros meios digitais são mais interativos e atendem com mais eficácia a questão da visualidade e de suporte com vídeos sinalizados, como, por exemplo, os recursos do Google ou até mesmo o Youtube. No entanto, a outra parcela de respostas, 46,6\% (7), mesmo salientando que gostam e acreditam ser uma plataforma virtual interessante, também apresentam as mesmas inquietações do primeiro grupo, que é a falta de acessibilidade, destacando que muito se tem a melhorar.

Essas considerações vão ao encontro da literatura especializada (CORRÊA; CRUZ, 2019), que evidencia a importância de os meios educacionais digitais apresentarem acessibilidade em diferentes áreas, no caso específico de usuários de língua de sinais, os recursos, como suporte de vídeo, telas interativas, janela com intérprete são imprescindíveis para o acesso e a manutenção dos usuários dentro do contexto educacional digital.

No que tange à segunda pergunta: Quais foram suas dificuldades ao utilizar os recursos tecnológicos e a plataforma Moodle?, as respostas nos encaminham para três categorias: a) 13,30\% (2) não encontraram dificuldades; b) 13,33\% (2) encontraram dificuldades razoáveis e c) 73,33\% (11) encontraram dificuldades.

No grupo de respostas considerando a primeira categoria observaremos que dois acadêmicos responderam não apresentarem dificuldades, sendo:

P8: No meu caso não tive dificuldades por saber procurar e encontrar o que eu precisava.

P11: Não tive muitas dificuldades ao utilizar, pois já tive experiências com os recursos tecnológicos e as plataformas antes. Com a plataforma Moodle, eu tive um pouco.

Com base nas respostas, podemos inferir que os participantes em questão têm experiências anteriores com a modalidade de ensino a distância e/ou 
realizaram cursos utilizando esta plataforma educacional.

Na categoria em que encontra dificuldades consideradas razoáveis, obtivemos um percentual de 13,30\% (2), mesma quantidade que a primeira categoria: P12 (repetição da resposta 1), como se observa na seguinte resposta: P12: [..] o Moodle, e para mim é razoável de uso Moodle [...].

No terceiro conjunto de respostas, categorizamos como a maioria dos participantes 73,33 \% (11) que afirmam apresentarem dificuldades em manusear a plataforma. Para uma melhor organização das respostas, realizamos duas categorias conceituais para análise descritiva-explicativa, sendo: a) falta de tradução em Libras dos materiais e b) falta de suporte no decorrer da disciplina - prática e conceitual.

\begin{abstract}
P2: Sendo aluna surda, encontro poucos textos repassados nos arquivos e não tem a tradução de libras para compreender melhor. P5: De exportar os arquivos das atividades, responder as perguntas da plataforma dos outros usuários e tirar dúvidas com professor durante o fórum.

P10: Dificuldades de abrir ou clicar qualquer arquivo ou opção.

P9: Eu tenho dificuldades e barreiras sim, dependendo do que tem nos recursos tecnológicos e a plataforma Moodle. Por exemplo, quando eu pesquiso na internet, lendo os textos e consigo entender, mas minha barreira é se expressar e escrever o português. Outro exemplo, o dicionário virtual, a palavra manifestação, eu leio e entendo o significado com dois sentidos diferentes. Mas com a frase formal e tudo, eu não consigo entender nem o contexto, por isso tenho barreira no português. Eu sempre tenho dúvidas e sempre pergunto para minha família, minha mãe, etc.
\end{abstract}

Em conformidade com as respostas obtidas e a categorização realizada: a) falta de tradução em libras dos materiais, b) falta de suporte no decorrer da disciplina, a fim de evidenciar essa lacuna enfatizando estudos especializados na área, recorre-se aos estudos de Fernandes e Moreira (2017) que há anos vêm discutindo e evidenciando a importância do letramento para surdos acadêmicos, uma vez que estão no âmbito de uma discussão linguística e política sobre a falta de acesso real de inclusão para aprendizes surdos, com dificuldades na leitura e escrita do português e experiências pouco significativas em língua de sinais.

Torna-se importante destacar, ao reportarmo-nos à característica essencial da EAD, híbrida ou não, que o aluno se envolve na atividade de aprendizagem em um local onde o professor não está fisicamente presente. Dessa forma, nesse afastamento entre professor e aluno, a EAD carece de apoiar-se em meios e no uso de tecnologias para transmitir a mensagem do professor para o aluno. 
Na EAD, as ferramentas utilizadas para a atualização vão desde o material impresso até a internet, passando pela televisão, rádio, fitas de vídeo e áudio, CD-ROM, orientação por computador, videoconferências, teleconferências, correio eletrônico, fórum, chat, orientações presenciais e correspondência, proporcionando, assim, ao aluno, uma oportunidade de atualização sem afastamento de suas atividades.

Portanto, a EAD surge como ferramenta estratégica importante de sobrevivência pessoal e profissional, como consequência da globalização, do aumento assustador de níveis de concorrência e do agravamento da desigualdade social no país (OLIVEIRA, 2007). Saber utilizar essas ferramentas, em especial as mais essenciais, também pode se tornar uma forma de emancipação e de formação para os alunos surdos.

Tais adaptações se fazem necessárias em razão de a sociedade atual requerer um novo educador, exigir do docente não mais uma transmissão de conhecimento, mas um docente multiplicador de conhecimento, que dê conta de linguagens diversificadas. Mais do que aprender a fazer, ele deve ser formado para aprender a aprender sem ocupar a posição de única fonte do saber de "forma tradicional e autoritária".

Nesse sentido, necessita-se de conhecimento para o uso das Novas Tecnologias de Informação e Comunicação (NTIC) para melhorar a eficiência e a eficácia do ensino-aprendizagem e, assim, a atuação e o crescimento profissional dos docentes, já que quando os dados foram analisados sobre a concordância ou não da plataforma virtual ser um lugar de aprendizado, todos os participantes investigados concordaram que a plataforma Moodle pode ser um bom lugar para as interações entre alunos e professores, considerando o avanço e utilização da tecnologia, cada vez mais presente nas instituições de ensino. Mas, para isso, o professor precisa dominar os recursos tecnológicos, "uma vez que o professor pode adotar em sua prática cotidiana uma postura que subsidia e estimula o aluno a refletir sobre o que significa comunicar-se em nossa sociedade, como também aprender a manipular tecnicamente as linguagens e a tecnologia" (CHIAPINNI, 2005, p. 278).

\section{Considerações finais}

De acordo com os dados desta pesquisa, infere-se que a Plataforma Moodle é, de fato, uma ferramenta muito importante no processo educativo, mesmo percebendo que a falta de domínio da língua portuguesa, comumente relatada 
pelos surdos, pode interferir na participação nos fóruns e discussões nesse ambiente virtual. A maioria dos alunos participantes optou por responder as questões em português, na modalidade escrita, mesmo podendo escolher a opção em responder em Libras, registrada em vídeo, fato este que traz à tona uma reflexão importante sobre possíveis preferências do aluno surdo na forma de registrar o seu pensamento.

Além disso, cabe esclarecer que o Moodle ainda não é totalmente bilíngue e acessível, algumas alterações no sistema deveriam ser realizadas para uma maior participação dos alunos surdos.

Após analisar os dados desta pesquisa e quando somados aos resultados dos estudos de Pereira e Cezar (2019), quanto à análise das salas virtuais na plataforma Moodle para acadêmicos surdos, constata-se a falta de materiais traduzidos em Libras na turma de 2018, porém esse aspecto foi modificado no ano seguinte, trazendo mais acessibilidade, o que poderia despertar o interesse dos alunos para a utilização da plataforma, principalmente com sinalários específicos relacionados ao conteúdo acadêmico trabalhado pelo professor. A padronização do Moodle para as demais disciplinas se faz necessária, pois cada professor utiliza o ambiente de uma forma, o que pode confundir alguns alunos com dificuldade de utilização do Sistema. Materiais didáticos com informações mais visuais podem ser inseridos no Moodle, como as tirinhas e história em quadrinhos, para a fixação dos conteúdos, exemplificações e atividades complementares.

Além disso, esses recursos, como as plataformas Moodle devem ser incorporadas ao cotidiano das aulas trazendo desafios na medida em que favorecem o desenvolvimento de novas situações acadêmicas, ampliando o acesso à informação, à participação, à ampliação de redes para o processo de ensino e de aprendizagem. Assim, os acadêmicos surdos podem ser mais confiantes e capazes de utilizar tanto a Língua Brasileira de Sinais (L1) quanto a Língua Portuguesa (L2) na sua comunicação, em diferentes espaços, garantindo acessibilidade na aprendizagem e no ensino, colaborando na formação de surdos bilíngues.

\section{Referências}

AMORIM, M. L. C.; SOUZA, F. D. F.; GOMES, A. S. Educação a Distância para surdos: acessibilidade de plataformas virtuais de aprendizagem. Curitiba: Appris, 2016.

ARCOVERDE, R. D. de L. Tecnologias digitais: novo espaço interativo na produção escrita dos surdos. Cad. Cedes, v. 26, n. 69, p. 251-267, 2006. 
BAKHTIN, M. [VOLOSHINOV, V. N]. [1929] Marxismo e Filosofia da Linguagem. 12. ed. São Paulo: Hucitec, 2006.

BAKHTIN. M. Os gêneros do discurso. In: BAKHTIN. M. Estética da criação verbal. Tradução: Maria Ermantina Galvão Gomes Pereira. São Paulo: Martins Fontes, 1992.

BISOL, C.; SPERB, T. M. Discursos sobre a surdez: deficiência, diferença, singularidade e construção de sentido. Psicologia: Teoria e Pesquisa, v. 26, n. 1, p. 07-13, Brasília, 2010.

BLOMMAERT, J. \& RAMPTON, B. Language and Superdiversity. A position paper. Working Papers in Urban Language and Literacies, Paper 70, v. 13, n. 2, London: Tilburg University and King's College, 2011.

BRASIL. Lei n $n^{\circ} 10.436$, de 24 de abril de 2002. Dispõe sobre a Língua Brasileira de Sinais e dá outras providências. Diário Oficial da União, Brasília, 25 de abril de 2002.

BRASIL. Decreto $n^{\circ} 5.626$, de 22 de dezembro de 2005. Regulamenta a Lei $n^{\circ} 10.436$, de 24 de abril de 2002, que dispõe sobre a Língua Brasileira de Sinais - libras, e o art. 18 da Lei n 10.098 , de 19 de dezembro de 2000. Diário Oficial da União, Brasília, 23 de dezembro de 2005.

BRASIL. Ministério da Educação. Censo da Educação Superior 2017. Divulgação dos principais resultados. 2018. Disponível em: http://portal.mec.gov.br/docman/setembro-2018-pdf/97041-apresentac-a-o-censo-superior-u-Itimo/file. Acesso em: 12 maio 2019.

BRASIL. Ministério da Educação. Secretaria de Educação a Distância. Referenciais de Qualidade para Educação Superior a Distância. 2007. Disponível em: http://portal.mec.gov.br/seed/arquivos/pdf/legislacao/refead1.pdf. Acesso em: 12 maio 2019.

CESAR, A. L.; CAVALCANTI, M. C. Do singular para o multifacetado: o conceito de língua como caleidoscópio. In: CAVALCANTI, M. C.; BORTONIRICARDO, S. M. (Org.) Transculturalidade, linguagem e educação. Campinas: Mercado de Letras, 2007, p. 45-66.

CORREAA, Y; CRUZ, C. R. (Org.). Língua Brasileira de Sinais e Tecnologias Digitais. Porto Alegre: Penso, 2019.

CHIAPPINI, L. Reinvenção da catedral: língua, literatura, comunicação: novas tecnologias e políticas de ensino. São Paulo: Cortez, 2005, p. 95-100.

FARACO, C. A. Linguagem \& diálogo. As ideias linguísticas do círculo de Bakhtin. São Paulo: Parábola, 2009.

FERNANDES, S; MOREIRA, L. C. Políticas de Educação Bilíngue para estudantes surdos: contribuições ao letramento acadêmico no ensino superior. Educar em Revista [online], n. esp. 3, p. 127-150, 2017.

FISCHER, K; CEZAR, K. P. L. O uso dos recursos tecnológicos no ensino bilíngue para acadêmicos surdos. Relatório de Iniciação Científica. Curitiba: UFPR, 2019.

GESSER, A. Do patológico ao cultural na surdez: para além de um e de outro ou para uma reflexão crítica dos paradigmas. Trab. Ling. Aplic., Campinas, v. 47, n. 1, p. 223-239, jan-jun. 2008.

GESSER, A. LIBRAS? Que língua é essa? Crenças e preconceitos em torno da língua de sinais e da realidade surda. São Paulo: Parábola, 2009.

GIL, A. C. Como elaborar projetos de pesquisa. 4. ed. São Paulo: Atlas, 2007.

GOETTERT, N. Tecnologias digitais e estratégias comunicacionais de surdos: da vitalidade 
da língua de sinais à necessidade da língua escrita. 2014. Dissertação (Mestrado) - Programa de Pós-graduação em Educação, Universidade do Vale do Rio dos Sinos, São Leopoldo, 2014.

KENSKI, V. M. Tecnologias e ensino presencial e a distância. Campinas: Papirus, 2004.

KENSKI, V. M. O papel do professor na sociedade digital. In: CASTRO, A. D.; CARVALHO, A. M. P. (Org.). Ensinar a ensinar: didática para a escola fundamental e média. São Paulo: Pioneira Thomson Learning, 2001.

KUBASKI, C; MORAES, V. P. O Bilinguismo como proposta educacional para crianças surdas; IX Congresso nacional de educação - EDUCERE; III Encontro sul brasileiro de psicopedagogia. PUCPR, 2009.

LODI, A. C. B. Uma leitura enunciativa da língua brasileira de sinais: o gênero conto de fadas. DELTA, v. 20, n. 2, p. 281-230, 2004. Disponível em: https://www.scielo.br/pdf/delta/v20n2/24271. pdf. Acesso em: 12 maio 2019.

LOPES, L. P. M. Afinal o que é Linguística Aplicada? In: Luiz P. Moita Lopes (Org.). Oficina de Linguística Aplicada. Campinas/SP: Mercado de Letras: 1996, p. 17-26.

LOPES, L. P. M. Da aplicação de linguística à linguística aplicada indisciplinar. In: Regina C. Pereira \& Pilar Roca (Orgs.). Linguística Aplicada: um caminho com diferentes acesos. São Paulo: Contexto: 2009, p. 1-24.

NOGUEIRA, R. A. Mudanças na sociedade contemporâneas. Mundo Jovem. São Paulo, n. 123, fev. 2002.

OLIVEIRA, M. A. N. Educação a Distância como estratégia para a educação permanente: possibilidades e desafios. Revista Brasileira de Enfermagem, Brasília, n. 60, v. 5, p. 585-589, set-out, 2007.

PEREIRA, A.; CEZAR, K. P. L. Gêneros Digitais e a escrita formal dos surdos. Relatório de Iniciação Científica. Curitiba: UFPR, 2019.

PERLIN, G. O lugar da cultura surda. In: THOMA, A. da S.; LOPES, M. C. (Orgs.). A invenção da surdez: cultura, alteridade, identidade e diferença no campo da educação. Santa Cruz do Sul: EDUNISC, 2004.

QUADROS, R. M. Educação de surdos: a aquisição da linguagem. Porto Alegre: Artes Médicas, 1997.

QUADROS, R. M.; KARNOPP, L. B. Língua de Sinais Brasileira: Estudos lingüísticos. Porto Alegre: Artmed, 2004.

SIGNORINI, I. e M. C. CAVALCANTI. Linguística Aplicada e Transdisciplinaridade: Questões e Perspectivas. Campinas: Mercado de Letras, 1998.

SILVA, A. R. Fundamentos da Educação Especial e Inclusiva. Apostila do IESB - Instituto de Educação Superior do Brasil. Sobral, 2010, p. 09-10.

SKLIAR, C. Uma perspectiva sócio-histórica sobre a Psicologia e a educação dos surdos. In: C. Skliar (Org.). Educação \& inclusão: abordagens sócio-antropológicas em Educação Especial. Porto Alegre: Mediação, 1997, p. 105-153.

SKLIAR, C. (Org). A surdez: um olhar sobre as diferenças. Porto Alegre: Mediação, 2005. STROBEL, K. História da educação de surdos. UFSC. Universidade Federal de Santa Catarina. Licenciatura em Letras Libras na modalidade a distância. 2009. Disponível em: http://www.libras. 
ufsc.br/colecaoLetrasLibras/eixoFormacaoEspecifica/historiaDaEducacaoDeSurdos/assets/258/ TextoBase_HistoriaEducacaoSurdos.pdf. Acesso em: 14 maio 2019.

STUMPF, M. R. Educação de surdos e novas tecnologias. Universidade Federal de Santa Catarina. Licenciatura e Bacharelado em Letras Libras na Modalidade a Distância. Florianopolis, 2010.

VERTOVEC, Steven. Super-diversity and its implications. Ethnic and Racial Studies, London, V. 30, n. 6, p. 1024-1054, 2007.

VYGOTSKY, L. S. (1984). Formação social da mente. São Paulo: Martins Fontes 1984.

\section{Sobre os autores}

Kelly Priscilla Lóddo Cezar - Pós-doutora pela Universidade Estadual do Oeste do Paraná (UNIOESTE). Doutora pelo Programa de Linguística e Língua Portuguesa da Universidade Estadual Paulista Júlio de Mesquita Filho (UNESP-FClar/Araraquara). Professora Adjunta da Universidade Federal do Paraná (UFPR), campus de Curitiba. Participante do Grupo de pesquisa Formação de professores em línguas (UFPR). Docente do curso de licenciatura em letras libras (UFPR). Membro da Equipe Multidisciplinar (área de acessibilidade linguística) da UAB/CIPEAD/UFPR. E-mail para contato: kellyloddo@ufpr.br.

Adriano de Souza Pereira - Mestre em Distúrbios da Comunicação pela Universidade Tuiuti do Paraná (UTP). Graduado em Pedagogia pelo Centro Universitário Internacional (UNINTER). Atualmente, acadêmico do curso de licenciatura em letras libras em Licenciatura pela Universidade Federal do Paraná (UFPR). Desde 2018, aluno-pesquisador do Programa de Iniciação científica e Integração Acadêmica da Universidade Federal do Paraná (UFPR 2018-2019/2018-2020) vinculada ao projeto de pesquisa Gêneros Textuais e o Ensino para Surdos. E-mail para contato: adriano1509pereira@gmail.com.

Katherine Fischer - Pós-graduanda em Educação Especial com ênfase em Deficiência Auditiva pela Faculdade Educacional da Lapa (FAEL). Pós-graduada em Gestão de Projetos pela Universidade de São Paulo (USP). Graduada em Arquitetura e Urbanismo pela Universidade Positivo (UP). Atualmente, acadêmica do curso de licenciatura em letras libras em Licenciatura pela Universidade Federal do Paraná (UFPR). Desde 2018, aluna-pesquisadora do Programa de Iniciação científica e Integração Acadêmica da Universidade Federal do Paraná (UFPR 2018-2019/2018-2020) vinculada ao projeto de pesquisa Gêneros Textuais e o Ensino para Surdos. E-mail para contato: kathe.fischer@ gmail.com. 